\title{
FORMAR, UM ACONTECIMENTO: SUBTRAIR VARIANDO EM MODOS ESQUIZO*
}

\author{
Margareth Ap. Sacramento Rotondo \\ Giovani Cammarota
}

\begin{abstract}
Resumo
Este artigo discute a formação docente como acontecimento tomando como meio um episódio em que pesquisadoras e pesquisadores são convidados a participar de uma reunião pedagógica para discutir os algoritmos da subtração em uma escola da rede pública de Juiz de Fora/MG. Na escola em questão, dois modos de subtrair eram ensinados: o do empréstimo e o da compensação. A problematização dos algoritmos se dá segundo uma aliança com um modo esquizo de subtrair: ao mesmo tempo que embaralha os códigos já reconhecidos do empréstimo e da compensação, ele não está canonizado como algoritmo escolar. Tais modos de subtrair nos convocam a discutir três modos de formar: um primeiro, instrumental, ligado a uma idealidade dada por uma imagem dogmática do pensamento; um segundo, reflexivo, ligado à constituição de um modo geral de pensar que aciona os esquemas de representação como modo de ação; um terceiro, esquizo, que dá a pensar o acontecimento. Formar, um acontecimento, se constitui numa afirmação do acaso absoluto, do devir: um único lance de dados que faz a formação encontrar sua própria necessidade. Essa discussão se enreda na esteira das filosofias da diferença, em especial a de Gilles Deleuze e Félix Guattari.
\end{abstract}

Palavras-chave: formação docente; acontecimento e acaso; algoritmos da subtração; educação matemática.

\section{Pesquisar: um meio entre subtrair e formar}

"Mas um meio é feito de qualidades, substância, potências e acontecimentos."

(Gilles Deleure)

Numa escola, parceira de uma pesquisa ${ }^{1}$, um inusitado convida: subtrair, uma máquina, funciona ou emprestando ou compensando e aciona conceitos matemáticos,

\footnotetext{
* DOI - 10.29388/978-65-86678-51-2-0-f.437-450

${ }^{1} \mathrm{O}$ episódio que inspira esse texto é parte da pesquisa intitulada "Formação de professores que ensinam matemática: produção do conhecimento matemático através do dispositivo-oficina e seus efeitos no ensino e na aprendizagem da matemática na escola" (CAPES/FAPEMIG, Processo no APQ-03416-12), coordenada por Margareth Ap. Sacramento Rotondo com a colaboração do professor Giovani Cammarota. Trata-se de um momento da pesquisa em que uma coordenadora dos anos iniciais do ensino fundamental solicita à equipe da pesquisa presença em uma reunião pedagógica para discutir com professoras e professores dois modos de ensinar subtração que circulavam na escola naquele momento: o método do empréstimo e o método da compensação. A equipe, então, toma como dispositivo para a reunião a apresentação dos algoritmos do empréstimo, da compensação e o modo de Adriana, apenas recitando os passos desses métodos. A estranheza de recitar o modo de Adriana, não escolarizado e desconhecido para aquele grupo, engendra uma discussão em torno da subtração e dos modos de operar dos algoritmos que habitam a escola (ROTONDO; CAMMAROTA, 2016).
} 
retirar ou completar. Professoras de alguns anos ensinam a subtrair retirando; em outros anos, professoras ensinam a subtrair completando. Da coordenação da escola vem uma solicitação: a de que a equipe da pesquisa esteja presente em uma reunião pedagógica para discutir com professoras e professores os modos de subtrair que circulam pela escola naquele momento. Encontro com um problema: subtrair retirando on subtrair completando ou outros tantos modos?

Em uma reunião pedagógica, professoras e professores, pesquisadoras e pesquisadores. Para reunir pesquisar e escolar, um dispositivo é colocado em exercício: recitar métodos para subtrair sem explicitar qualquer relação da técnica com a operação ou com o sistema de numeração decimal. Recitar métodos para subtrair. um conjunto de passos falados em voz alta.

Título na lousa: método do empréstimo. Vamos fazer trezentos e noventa e cinco menos cento e setenta e seis. Então, cinco menos seis não dá para subtrair, para resolver o cinco pede emprestado ao nove que vira oito e o cinco, quinze. Agora sim, quinze menos seis dá nove, oito menos sete dá um e três menos um, dois. Restam durentos e dezenove. Simples assim!

Reunir pesquisar e escolar: recitar método da compensação. Novo título vem: método da compensação. E a recitação retorna junto ao funcionamento silencioso de outra máquina. Vamos faz̧er a mesma conta, agora usando o método da compensação. Então, seis para chegar ao cinco não dá. Para resolver isto o cinco vira quinze e o sete vira oito. Agora sim: seis para quinze são nove, oito para o nove é um e um para três são dois. E a diferença será dužentos e dezenove.

$\mathrm{Na}$ lousa, um novo e último título: modo da Adriana. Vamos faz̧er a mesma operação pelo modo da Adriana. Adriana foi minha aluna quando, anos atrás, eu dava aulas particulares. Pelo modo da Adriana, trezentos e noventa e cinco menos cento e setenta e seis funciona assim: cinco menos seis dá menos um, nove menos sete dá dois e três menos um, dois. Como resultado inicial temos dois, dois e menos um. Como não dá para ficar menos um aqui nas unidades, somamos dez. unidades. Dez mais o menos um é igual a nove. Já que somei dez unidades, tiro uma dezena do dois do resultado inicial, que vira uma dezena. Então, o resultado final é durentos e dezenove.

Ocupar com sala de aula de matemática nos anos iniciais encontrando problema com processos formativos docentes. Habitar a escola para dar vida a uma proposta: dispor a professoras de matemática dos anos iniciais e a pesquisadoras e pesquisadores espaço e tempo para estar em processo formativo com suas salas de aula. Abalar processos formativos com problemas inventados com matemáticas: elo entre um pesquisar e um escolar. Experimentar processos formativos com o que se passa em salas de aulas de matemática dos anos iniciais: encontro de professoras, pesquisadoras, pesquisadores, alunas, alunos e matemática.

$\mathrm{Na}$ escola, um inusitado convida: processo formativo, uma máquina: processos formativos retirando ou processos formativos completando ou processos formativos esquizo $^{2}$.

\footnotetext{
2 "Deleuze e Guattari usam os termos "esquizo", "fluxo esquizo", "esquiza", "movimento esquiza" e também "esquizofrênico" ao se referirem ao movimento de embaralhamento de códigos, numa relação com o fora, de
} 
Uma escola produz um problema com formação: produzir processo formativo emprestando ou produzir processo formativo compensando ou processos formativos esquizo. A máquina posta a funcionar irá retirar ou irá completar ou funcionará de outros tantos modos. Formar de dois modos distintos, que existir produz? E num modo esquizo, que existir produz? Formar de dois modos distintos, a que se destina? E num modo esquizo, a que se destina? Reunir pesquisar e escolar, um eco: formar retirando ou formar completando ou formar embaralhando os códigos?

Reunir formar e escolar: ativar método do empréstimo. Vamos fazer formação atenta no que acontece menos formação a ser inventada. Então, no que acontece não dá para subtrair o a ser inventada, para resolver a atenção recebe emprestado uma imagem a seguir, um ideal. Agora sim, imagem ideal menos o a ser inventada, modelo ideal de professora ou de professor. Resta o que varia em invenção. Simples assim!

Reunir formar e escolar: ativar método da compensação. Novo título vem: método da compensação. Vamos fazer novamente formação atenta no que acontece menos formação a ser inventada. E a recitação retorna junto ao funcionamento silencioso de outra máquina. Então, aquilo a ser inventado para chegar ao acontecimento, não pode. Para resolver isto o que se dá no que acontece vira forma ideal e aquilo a ser inventado vira modelo a seguir. Agora sim: $o$ modelo a seguir para forma ideal é o invariante. E o resultado será modelo ideal de professora ou de professor.

No existir do processo, um novo e último título: modo esquizo. Vamos fazer a mesma operação pelo modo do esquizo. Pelo modo esquizo, vamos fazer formação atenta no que acontece menos formação a ser inventada: atenção ao que acontece menos a ser inventada se conectam no que acontece em pura invenção, torcem um formar. Como resultado inicial temos atenção ao que passa e ao processo. Como não dá para ficar menos vida aqui no que existe, somamos problema a ser encontrado em processo. Atenção ao que se passa e ao processo mais vida no que existe, igual formação no movente, sempre em processo. Então, o resultado final não será final, sempre processual, no que se apresenta, em devir. Variar e inventar, sempre, eis a máquina esquizo em atenção ao que vem.

\section{Subtrair: uma maquinaria e suas engrenagens}

Subtrair: conceito matemático tipicamente trabalhado em anos iniciais do ensino fundamental. Aprender subtração se desdobra em dois problemas: um ligado ao funcionamento silencioso das máquinas que fazem funcionar e operar subtração emprestar e compensar - e outro que nos faz perguntar por uma relação que vai se estabelecendo com matemática, com subtração.

O que está em jogo no silencioso algoritmo que faz da subtração uma máquina de emprestar? Voltemos à recitação do empréstimo: nele, o que está em jogo é sempre um processo de retirada. Quer dizer, temos um subtraendo - 176 - que vai ser retirado do minuendo - 395. Por isso a pergunta recitada é sempre do tipo quanto é isso menos aquilo? Essa pergunta expressa a retirada e o resultado que aparece é o resto, ou seja, aquilo que

\footnotetext{
exteriorização. Para se referirem à doença esquizofrenia, eles utilizam o termo: "esquizofrenia artificial" ou
} “esquizofrênico artificial”." (CLARETO, ROTONDO, CAMMAROTA, 2018, p. 283). 
restou do minuendo quando dele retiramos o subtraendo. Então, para cada ordem do sistema de numeração decimal, efetua-se uma retirada. O problema surge quando uma ordem do sistema de numeração decimal não tem elementos suficientes para que a retirada seja efetuada: cinco menos seis não dá. É nesse empecilho que um dispositivo de troca entre as ordens do sistema de numeração decimal entra em jogo. Em 395, há 3 centenas, 9 dezenas e 5 cinco unidades. Mas também pode-se expressar 395 como 3 centenas, 8 dezenas e 15 unidades, trocando-se uma dezena por dez unidades. Esse é o dispositivo que dá apelido ao algoritmo, mas que funciona silenciosamente ao dizermos que o cinco pede emprestado ao nove que vira oito e o cinco, quinze. Trata-se mais de outro modo de expressão do próprio 395 do que de um empréstimo cuja devolução jamais acontece. É todo um sistema específico de troca que está escondido pelo modo como recitamos o empréstimo. É todo um trabalho com o sistema de numeração decimal que se esconde sob a alcunha do algoritmo.

O que está em jogo no silencioso algoritmo que faz da subtração uma máquina de compensar? Voltemos à recitação da compensação: nela, o que está em jogo é sempre um processo de completamento. O que está em jogo aqui é um subtraendo - 176 - que deve ser completado até que chegue ao valor do minuendo - 395. Por isso a pergunta recitada é sempre do tipo quanto falta a isso para chegar àquilo? Essa pergunta expressa um completamento e o resultado é a diferença, quer dizer, a diferença que separa a quantidade expressa pelo minuendo da quantidade expressa pelo subtraendo. Então, para cada ordem do sistema de numeração decimal, efetua-se um completamento. $O$ problema surge quando uma ordem do sistema de numeração decimal já possui mais elementos do que aquela que ela deve completar: seis para chegar ao cinco não dá. É nesse empecilho que surge um dispositivo sofisticado: dá-se ao cinco dez unidades, que passam a ser quinze. Com isso, resolvemos um primeiro problema: é possível, dentro do método da compensação, responder a seis para chegar a quinze. Ao mesmo tempo, cria-se um outro problema: ao darmos dez unidades ao 5 de 395, passamos a lidar com a quantidade 405. Para que essa ação seja compensada, é preciso que 176 também ganhe uma quantidade equivalente a dez unidades: é por isso que 176 ganha uma dezena e passamos a operar com 186. Quer dizer, o método da compensação desloca simultaneamente os dois números operados em dez unidades: é que ele parte do suposto de que a diferença, aquilo que procuramos ao efetuar uma subtração pelo método da compensação, se mantém a mesma quando fazemos 395 176 e 405 - 186. Desloca-se, mantendo-se uma distância invariante.

Subtrair, máquina de emprestar e máquina de compensar. coloca em jogo modos distintos de matematizar. Emprestar implica em retirar, extrair um resto, efetuar trocas entre ordens do sistema de numeração decimal. Compensar implicar em completar, extrair uma diferença, efetuar deslocamentos simultaneos dos números cuja diferença se quer extrair. Como um matematizar torna-se algoritmo? Em seu sentido mais usual, um algoritmo é um conjunto finito de regras, raciocínios e passos que, aplicados a um conjunto finito de dados, é capaz de resolver uma classe semelhante de problemas. Separados dos problemas de que são expressão, empréstimo e compensação tornam-se algoritmos, conjuntos de regras e passos, recitação. Escondem a maquinaria posta em funcionamento na ação mesma de recitar. Mas, se seguimos a pista segundo a qual "Só a expressão nos dá o procedimento" (DELEUZE; GUATTARI, 2015, p. 35), é no nível da expressão que os procedimentos, os conjuntos de 
regras e passos, as recitações precisam ser questionados. É que tais procedimentos são expressões de um campo em que subtrair aparece como força que instaura o problemático ${ }^{3}$.

Colocar o subtrair como problema em educação matemática no nível dos procedimentos nos leva a um caminho que, no mais das vezes, centra suas forças em duas perspectivas: a primeira procura responder à questão, tão recorrente em nosso tempo, em torno da eficácia, da eficiência e do desempenho de estratégias de ensino em que os algoritmos do empréstimo e da compensação aparecem. Essa perspectiva pode ser encontrada em Mello, quando a pesquisadora diz:

Se o algoritmo do empréstimo, em determinados casos, pode ser um gerador de erros, como pudemos observar, acreditamos que possa ser interessante o uso do algoritmo da compensaçáo como uma alternativa na tentativa de diminuir os erros dos alunos ao efetuar subtraç,oes. (MELLO, 2008b, p. 6).

Nas conclusões de sua dissertação de mestrado, a pesquisadora levanta a questão da eficiência.

Baseados nestes resultados, acreditamos que o uso do algoritmo da compensação poderia ser mais eficiente do que o uso do algoritmo do empréstimo, contornando problemas que os alunos enfrentam para efetuar subtrações. E, assim, respondemos positivamente nossa questão de pesquisa: "Se usássemos o algoritmo da compensação poderíamos diminuir os erros dos alunos do Ensino Fundamental ao efetuarem subtrações?”. (MELLO, 2008a, p. 124).

A própria questão respondida pela pesquisadora coloca um problema que é o da eficácia. Quer dizer, a educação matemática que aí se constitui parece compromissada com a fixação e obtenção de metas - muitas das vezes nomeadas como competências ou habilidades, mas nesse caso em particular se trata de uma meta mais específica, diminuir erros dos alunos ao efetuarem uma subtração-que, então, passam constituir uma problemática temporal - como atingir tal meta de aprendizagem em menos tempo - e uma problemática de desempenho - como atingir tal meta de aprendizagem diminuindo os percalços que são revelados pelos erros. Não parece surpresa que uma tal agenda de pesquisa esteja alinhada a um discurso econômico sobre a própria educação escolar: os parâmetros da eficácia, eficiência e desempenho aparecem como invariantes, como parâmetros abstratos gerais que estariam prontos a serem aplicados a distintos pontos do conjunto social.

A segunda perspectiva, em menor ou maior grau de afinidade com a primeira, responde pelo esquadrinhamento dos processos de desenvolvimento e aprendizagem das ideias matemáticas presentes quando da aprendizagem da subtração e seu algoritmo. É como se tal esquadrinhamento revelasse o percurso que um aluno precisa realizar necessariamente, invariavelmente para aprender a subtrair. Trabalhos como o de Vergnaud (1996) e de Nunes et al. (2009) operam nesse caminho. Trazendo referências da psicologia

${ }^{3} \mathrm{O}$ problemático se dá na ordem das afecções. "Há aí toda uma sorte de deformações, transmutações, passagem ao limite, operações onde cada figura designa um "acontecimento" [...] o problema é afectivo e inseparável das metamorfoses, gerações e criações na própria ciência. [...] o problema não é “obstáculo", é ultrapassagem do obstáculo, uma projeção, isto é, uma máquina de guerra.” (DELEUZE; GUATTARI; 2012, p. 26-27). 
do desenvolvimento, Nunes et al. (2009) trazem a subtração como conceito estruturado em um campo conceitual aditivo. É a partir desse campo conceitual que todo o esquadrinhamento da aprendizagem dos conceitos se dá. Nessa segunda perspectiva, abrese caminho para discutir, no âmbito da aprendizagem dos campos numéricos, a lógica subjacente aos algoritmos, pois

A independência entre a aprendizagem dos algoritmos e a compreensão de princípios lógicos está, portanto, claramente demonstrada. No entanto, isso não significa que essa separação seja desejável. Ao contrário, exatamente porque sabemos que a conexão entres essas duas habilidades pode não se desenvolver espontaneamente, um dos objetivos da educação deve ser promover a conexão entre a lógica da adição [ou subtração, já que se trata de um mesmo campo conceitual] e a habilidade de cálculo. (NUNES et al, 2009, p. 172-173, grifo nosso).

Há aqui um efeito que é importante salientar: uma vez esquadrinhado um caminho de aprendizagem como um caminho necessário e invariante, a habilidade de cálculo e os princípios lógicos que a constituem aparecem como domínios que podem ser distintos. É como se, de alguma maneira, o campo problemático inaugurado pelo subtrair se encontrasse separado em um conjunto de princípios e um conjunto de habilidades de cálculo que podem se descolar dos princípios. É como se os procedimentos não dissessem mais dos problemas que exprimem ou como se pudessem ser separados deles.

Mas como um campo problemático inaugurado pelo subtrair pode estar separado dos problemas que ele pode engendrar? É que todo o esquadrinhamento das máquinas de subtrair faz intervir na aprendizagem uma imagem dogmática do pensamento, reduzindo o pensamento a processos de representação e a aprendizagem a um processo de aquisição de saberes. É nesse sentido que o campo problemático inaugurado pelo subtrair é capturado por um postulado do saber, que "[...] designa apenas a generalidade do conceito ou a calma posse de uma regra das soluções.” (DELEUZE, 2006, p. 236). Subtrair, nesse sentido, designa a generalidade do conceito ou a calma posse de regras de soluções: nos algoritmos, regras que fazem emprestar, regras que fazem compensar.

Tomar a aprendizagem da subtração como um conjunto de regras e soluções a serem possuídas: eis um modo de compreensão da relação que temos com matemática. É o que Kastrup $(2005$; 2007) vai chamar de política de recognição.

No primeiro caso [o de uma política de recognição], a aprendizagem dobra-se a seus
resultados, o processo se submete ao produto. A aprendizagem é um meio de
obtenção de um saber. No caso da relação com a técnica, o que prevalece é o objetivo
de utilizá-la como veículo de dominação do mundo. Ocorre que, pretendendo
dominar, acaba-se, ao final, dominado. Aferra-se aos hábitos formados no trato com
o instrumento, como se a obediência a eles assegurasse o domínio do mundo. A
política que aí impera é uma política de recognição e ela se faz pela conversão, numa
espécie de lei transcendente, do hábito que foi constituído como regra imanente e
que, por sua natureza transitória, seria passível de ser abandonado. (KASTRUP, 2007,
p. 224).

Emprestar e compensar, dois modos de matematizar, duas técnicas para subtrair, em uma política de recognição, convertem um matematizar em algoritmo: recitação de 
regras e passos que, separados do campo problemático em que estão engendrados, são naturalizados, são tomados como lei transcendente.

O próprio texto de Kastrup, porém, traz duas chaves para uma problematização dessa política de recognição: reconectar o campo problemático do subtrair com aquilo que ele pode talvez seja fazer correr um avesso nessa política de recognição. Um avesso: tomar uma lei supostamente transcendente - emprestar e compensar - para dar a pensar hábitos que constituem leis imanentes em um algoritmo. É nesse sentido que tomar o dispositivo da recitação de algoritmos em uma reunião pedagógica se fez potente: ele deu a ver e falar todo um funcionamento silencioso da maquinaria da subtração, deu a ver e falar a constituição das leis imanentes a um modo singular de numerar, o do sistema de numeração decimal. É aí que utilizar os algoritmos não pode mais ser pensado como um modo de domínio sobre a subtração, quer dizer, a técnica não pode ser mais pensada como um domínio sobre o conceito. Um outro avesso se constitui, aquele que faz correr do algoritmo à técnica, ou melhor, do algoritmo a uma dimensão da técnica que aparece em seu sentido etimológico.

É que técnica, do grego tekhnikós, é aquilo é relativo à arte $e$ à ciência ou ao saber $e$ ao conhecimento ou à prática de uma profissão. Quer dizer, existe uma dimensão artística que está sempre junto à ciência, aos saberes e aos conhecimentos e práticas de uma profissão. Isso não significa tomar a arte como finalidade, mas, ao contrário, convida a pensar o processo inventivo, estético, de criação que está implicado em toda ciência, em todo saber, em todo conhecimento ou prática de uma profissão. Então, reconectar os algoritmos da subtração com o campo problemático que lhes constitui insinua sua dimensão inventiva e exige perguntar: que regras imanentes se constituem em uma técnica e constituem uma subtração? Um esquizo se insinua...

\section{Formar: uma maquinaria e suas engrenagens}

Formar uma ou um docente: proposta tipicamente trabalhada em cursos de licenciaturas tanto em universidades públicas quanto privadas, no Brasil e no exterior. Aprender a ser professora ou professor se desdobra em dois problemas: um ligado ao funcionamento silencioso das máquinas que fazem funcionar e operar formação emprestar e compensar - e outro que nos faz perguntar por uma relação que vai se estabelecendo com os saberes.

O que está em jogo no silencioso modo de funcionar que faz da formação uma máquina de emprestar? Voltemos à recitação do empréstimo: nele, o que está em jogo é sempre um processo de retirada. Quer dizer, de uma formação atenta no que acontece vai ser retirado uma formação a ser inventada. A pergunta é sempre do tipo que formação se dá quando daquela retiro esta? Essa pergunta expressa a retirada e o resultado que aparece é o resto, ou seja, aquilo que restou da formação atenta no que acontece quando dela retiramos a formação a ser inventada. Resta aquilo que varia em invenção.

O processo formativo apresenta-se, por esse modelo do empréstimo, quando uma formação atenta ao que acontece é controlada por discursos teóricos metodológicos que desejam antecipar-se aos acontecimentos e retirar a formação a ser inventada. Para tanto, essa formação atenta ao que acontece é desviada, muda de ordem, instrumentalizando-se de um "como fazer" para "o que pensar". Já não é mais da ordem do que acontece, a sua demanda agora é do 
âmbito da teoria e de um saber disciplinar idealizado, ou seja, de uma imagem a seguir. Para a retirada de uma formação a ser inventada exercita-se uma disciplinarização dos corpos e dos desejos, tornando as e os docentes executores de boas práticas, numa crença de que quando se sabe "como" e "o que" se ensina o outro aprenderá. O "como se ensina" estará fiado a práticas pedagógicas delineadas por um começo, meio e fim, ao cabo das quais, mesmo com um grupo enumerável e distinto de alunas e alunos, estes deverão aprender um tal conteúdo escolar já que lhes foi bem ensinado. Basta, pois, seguir o caminho bem traçado. Um caminho reto do ensinar garantirá um caminho reto do aprender. Para estas crenças há um discurso, um saber de referência na educação ou em seus fundamentos que justifica ações e também reações, sempre delineadas e esperadas, tanto dentro quanto fora da escola. Por muitas vezes ressoa nas reuniões de conselhos de classe e em salas de professoras e professores: fulano ainda é muito imaturo, dai seu insucesso escolar. Ou então, ele é tão desatento, aposto que é hiperativo! Ou, ele não tem base, não sabe nem sistema de numeração decimal, como é que vai aprender as operações? Ou, ele não presta atenção, já expliquei várias vezes, por isto erra. $\mathrm{Ou}$, os alunos têm que trabalhar primeiro no concreto, só depois no abstrato. Por outro lado, "o que se ensina” estará afiançado por saberes dogmáticos, muitas vezes chamados de científicos, porém, assépticos, separados do campo problemático que lhes tornaram o que são e por fim, hegemônica e universalmente acatados. Por aí estão nossa matemática "pura", nossa física "pura", nossa química "pura", mas também uma pedagogia "pura", uma psicologia "pura”,... uma ciência, para Deleuze, teoremática (DELEUZE; GUATTARI, 2012).

O que está em jogo no silencioso modo de funcionar que faz da formação uma máquina de compensar? Voltemos à recitação da compensação: nela, o que se efetua é sempre um processo de completamento, o que está em jogo é uma formação a ser inventada que deve ser completada até que chegue à formação atenta no que acontece. Por isso a pergunta recitada é sempre do tipo que formação se dá quando completo aquela para chegar nesta? $\mathrm{Na}$ impossibilidade de ação naquilo que está a ser inventado, já que não se completa aquilo que não se inventou, toma-se um modelo a seguir para se chegar a uma formação ideal. O procedimento faz com que formação a ser inventada passe a ser modelo a seguir e formação atenta no que acontece se torne uma formação ideal. Agindo por diferença, porém assumindo-a invariante.

O processo formativo apresenta-se pelo modelo da compensação quando uma formação a ser inventada é controlada por processos de conscientização que levam à sua instrumentalização através de um processo reflexivo, produzindo um controle, mas agora do sujeito reflexivo sobre si mesmo. Não mais uma disciplina do corpo e dos desejos, agora um controle interno, subjetivo, do sujeito docente sobre si mesmo. A reflexão a respeito de uma ação faz com que esse sujeito se torne consciente da boa forma a ser seguida, uma interiorização da vigilância, na produção de um corpo produtivo. Para chegar a essa boa forma expectada frente a um espelho da perfeição, a ou o docente toma a experiência de suas ações em salas de aula ou na escola, identifica faltas e desarranjos comparando o vivido na experiência com o modelo a seguir, busca ajustes, retorna à ação, agora uma ação refletida. Desloca-se do par formação atenta no que acontece - formação a ser inventada para formação do modelo a seguir - formação ideal, apostando no invariante. Desloca-se

${ }^{4} \mathrm{O}$ teoremático é da ordem da ciência régia, atua pela razão num espaço fechado, métrico ou estriado e, nessa interioridade, "[...] se vai de um gênero a suas espécies por diferenças específicas" e de "uma essência estável às propriedades que dela decorrem por dedução.” (DELEUZE; GUATTARI; 2012, p. 26-27). 
interiorizando um modelo como reflexo em um espelho que é a forma perfeita a ser alcançada. Como produto final, uma identidade: professor reflexivo, aquela ou aquele que será efeito e motor do processo ensino aprendizagem, já que age e reflete, produzindo nova ação, agora refletida, já que tem uma imagem necessária para atingir uma identidade, aquela identificada no espelho. Vive, pois uma circularidade, deslocando numa linha entre pontos equidistantes, numa racionalidade que se reflete - o que considera ser seu pensar e que, assim, irá levá-lo a um fazer ideal - ensinará bem. Há porém, uma distinção: a forma a ser alcançada já não é uma idealidade transcendente abstrata, e sim uma idealidade que se configura por e num modo de pensar, subjetiva: é o modo de pensar - refletir - que se torna o parâmetro, é uma forma vazia do pensamento que é "preenchida" por uma experiência docente qualquer. Aplicada sobre essa experiência docente qualquer, o modo reflexivo de pensar "faz" formação. Um modo muito mais sutil: ele não busca uma idealidade fora das coisas enquanto conteúdo, como no modo instrumental, sua busca é a que se preserva num modo de pensar que garante uma relação da subjetividade com os parâmetros de um pensar representacional para dar conta de uma forma ideal de ser professora ou professor: é aí que a formação se reencontra com um modelo a seguir, uma identidade que reflete, pois refletida.

Os dois modelos formativos ligam-se a uma moralidade já que assumem uma forma boa e muito bem intencionada, pois ideal, de ser professor ou professora e apóiamse em modos de aprender que tomam o conhecimento amparado a uma racionalidade que organiza e estabiliza os sentidos e significados, sejam elas de saberes disciplinares ou do campo da educação, da educação matemática. Ao chegarem à forma ideal ou à identidade refletida, ou melhor, ao almejarem tais idealidades, retiram, emprestando ou completando, o que varia em invenção e insistem no invariante: eis assim modelos dogmáticos de formação docente, normalmente tomados como instrumental e reflexivo.

\section{Subtrair e formar em modos esquizos}

Emprestar e compensar fazem funcionar uma máquina rente ao sistema de numeração decimal, rente à matemática e, com isso, fazem funcionar modos distintos de formar. É sempre isso: formar e saber constituem-se mutuamente, conhecer envolve uma relação consigo mesmo e com o mundo, envolve uma política cognitiva. Emprestar e compensar envolvem uma política cognitiva que apela ora para um empréstimo de imagens ideais, transcendentes, ora para um processo que compensa uma falta em busca de uma imagem refletida. Dois modos, uma política: a de que conhecer - conhecer matemática, conhecer subtração - se dá no ato da recognição e é recoberta por representações de uma idealidade ou de uma identidade. Formar, então, é um processo que se faz ao tomar emprestada uma idealidade docente ou uma identidade docente, completando o que falta ao sujeito rumo a um modelo ideal de professora ou professor.

Eis que uma esquizo Adriana invade uma reunião pedagógica. Esquizo: aquele que não reproduz os códigos sociais conforme uma imagem dogmática, conforme uma expectativa prévia, conforme uma tradição dada. Deleuze e Guattari dizem da relação do esquizo com os códigos sociais: 
O esquizo dispõe de modos de marcação que lhe são próprios, pois, primeiramente, dispõe de um código de registro particular que não coincide como o código social ou que só coincide com ele a fim de parodiá-lo. [...] Dir-se-ia que o esquizofrênico passa de um código a outro, que ele embaralha todos os códigos, num deslizamento rápido, conforme as questões que se lhe apresentam, jamais dando seguidamente a mesma explicação, não invocando a mesma genealogia, não registrando da mesma maneira o mesmo acontecimento [...]. (DELEUZE; GUATTARI, 2011, p. 29).

Um modo de subtrair recitado em uma reunião pedagógica aciona um embaralhamento dos códigos de algoritmos da subtração. Da reunião pedagógica, um eco de professoras e professores convocados a dizer: mas ela já sabe número negativo no $4^{\circ}$ ano? $A$ professora já ensinou isso? Mas de onde ela tirou que tem que somar 10 na ordem que está com o resultado negativo? E por que ela tira um na ordem seguinte?Um esquizo coloca um problema: na impossibilidade de lançar mão de um conjunto de regras transcendentes daquele modo de subtrair, só é possível produzir com ele um conjunto de regras imanentes, transitórias, passíveis de serem abandonadas. Um "mesmo" acontecimento, subtração, não é explicado nem registado da mesma maneira, em modos usuais, mas em variação.

Eis que uma esquizo Adriana ${ }^{5}$ rompe fluxos habituais de uma subtração que empresta e compensa, embaralhando esses modos canônicos. Tal modo não aciona as imagens que temos do que é subtrair, não empresta, não compensa. Fica no acontecimento, afirma o acaso. "Saber afirmar o acaso é saber jogar." (DELEUZE, 2018, p. 38). Tal modo encontra com um problema: o que há ainda a se produzir quando falamos em subtrair? O que há ainda a se produzir em processos formativos? Uma abertura no que acontece. Esquizo Adriana coloca em jogo outra política: fazendo elidir o vínculo do conhecer com uma imagem ideal, constitui-se uma fenda que convoca uma invenção de si e do mundo, convoca o deslocamento do formar e do subtrair para outras searas.

Formação, um tornar-se, uma processualidade, se afina com a invenção e não com a constituição de uma identidade que seria dada por uma instrumentalização ou um processo de reflexão:

O 'chegar a ser o que se é' não está agora do lado da lógica identitária do autodescobrimento, do autoconhecimento ou da auto realização, mas do lado da lógica desidentificadora da invenção. Uma invenção, não obstante, que não se passa a partir da perspectiva da liberdade criadora do gênio, da soberania de um sujeito capaz de criar-se a si próprio, mas a partir da perspectiva da experiência, ou melhor, da experimentação. (LARROSA, 2005, p. 66).

Um processo estético e ético: produção de uma fenda naquilo que nos separa do caos. Nos debatemos contra o caos embebidos em opiniões prontas. Será mais bem sucedido e produtivo neste ou naquele modelo. Será boa professora ou bom professor se agir de tal modo. Se da próxima vez fizer deste outro modo, terei mais êxito, ensinarei melhor. Seres cheios de boa vontade, amparados em opiniões. "O belo e o bem não cessam de nos reconduzir à transcendência.

${ }^{5}$ Vale aqui ressaltar que não se trata mais da aluna de quarto ano que resolveu uma subtração de modo inusitado em uma aula particular. Não mais se identifica. Esquizo Adriana, uma composição: uma aluna e um professor e uma aula particular e um saber escolar e processos formativos e reunião docente e professoras e professores e pesquisar e matemáticas e saber matemático escolar ... todos embaralhados. Adriana não funciona como sujeito ou identidade. Ao contrário, "Guattari mosta [...] que ele [ou Adriana] não representa um sujeito, mas diagramatiza um agenciamento; não sobrecodifica os enunciados, mas os retém, pelo contrário, para que não vacilem sob a tirania de constelações semiológicas ditas significantes." (DELEUZE, 2016, p. 85). 
É como se a opinião verdadeira exigisse um saber que ela todavia destituiu.” (DELEUZE; GUATTARI; 2010, p. 177).

Eis que uma esquizo Adriana rompe fluxos habituais instaurando outros modos noutras políticas. Uma política cognitiva inventiva: em que implica uma esquizo Adriana? Que maquinaria do saber põe a funcionar? Que maquinaria formar põe a funcionar? Uma esquizo Adriana e outro modo, co-produções e efeitos de práticas cognitivas, apresentam o reconhecimento como pousos de estabilização da cognição, e não como ponto final a que a cognição se submete. Fazem pensar tantos outros métodos inventados e por serem inventados, fazem pensar na dimensão inventiva da produção de uma técnica. Uma esquizo Adriana e outro modo, co-produções e efeitos de processos formativos, apresentam numa forma docente pouso de estabilizações, sempre prenhe de novos nascimentos, em devir. Fazem pensar formação no cultivo da compreensão de matemática como produção que se faz no ato de conhecer. Em ambos, uma luta contra o caos, agora não mais amparados na opinião que nos protegia, mas numa "[...] afinidade com o inimigo" (DELEUZE; GUATTARI, 2010, p. 261). Afinar-se com o inimigo na produção de conhecimento e no processo formativo é do âmbito do problemático, do não reconhecimento e da insistência no que varia, no que acontece. Nada de crença no fim, nada de reconhecer ou ressentir e nada de insistir "[...] [n] o ressentimento na repetição dos lances, [n] a má consciência na crença em um fim” (DELEUZE, 2018, p. 41, grifo nosso). Um só lance, aquele que se apresenta no acontecimento. Nada de emprestarinstrumentalizar ou completar-refletir, mas embaralhar códigos naquilo que acontece, ficar no meio. "Há muitos números segundo probabilidades crescentes ou decrescentes, mas um único do acaso como tal, um único número fatal que reúne todos os fragmentos do acaso, como o meio-dia reúne todos os membros esparsos de meia-noite." (DELEUZE, 2018, p. 40).

Uma esquizo Adriana desloca uma política cognitiva, afirma todo o acaso de uma vez só: numa invenção, subtrair se reconecta com seu campo de problemas. Emprestar e compensar encontram de novo e de novo sua própria potência: os procedimentos algorítmicos são expressões de um campo problemático instaurado por um modo de numerar - com base dez, de modo posicional, com presença do zero, escrevendo os números segundo princípios aditivo e multiplicativo. É toda uma imagem representativa do pensamento e da matemática que são deslocados:

[...] quando o pensamento assume as condições de um encontro efetivo, de uma autêntica conexão com o fora, então ele afirma o imprevisível ou o inesperado, acampa sobre um chão movediço que ele não domina e ganha daí sua necessidade. Pensar nasce de um acaso, pensar é sempre circunstancial, relativo a um acontecimento que sobrevém ao pensamento. (ZOURABICHVILI, 2016, p. 52).

Emprestar e compensar, verbos de um subtrair e verbos de um formar implicam outro verbo: reconhecer num saber e num formar. Esquizo Adriana, um exercício com subtrair tomado como ação de produzir-se e de produzir matemática implica outros verbos: inventar, problematizar, pensar, existir. Formar, um acontecimento:

Acontece alguma coisa que muda tudo, que desloca as potências e as capacidades. O acontecimento em Deleuze é primeiro redistribuição das potências [...]. Através do 
acontecimento, tudo recomeça, mas de outro modo; somos redistribuídos, às vezes reengendrados até de modo irreconhecível. Tudo se repete, mas distribuído de outro modo, repartido de outro modo, nossas potências sendo incessantemente revolvidas, retomadas, segundo novas dimensões. Nesse sentido, "a repetição é a potência da diferença". (LAPOUJADE, 2015, p. 67-68).

Sim, acontece alguma coisa que muda tudo no campo da produção do conhecimento matemático ${ }^{6}$, que desloca as potências e as capacidades de produção deste saber e dos processos formativos a ele correlatos. Daquela reunião veio: sempre fiz por empréstimo; ah não, compensação é muito mais fácil; pois é, meu marido faz.por compensação, tenta me explicar, finjo que entendo; isso que Adriana fer, pode? E caem, por fim, em: mas então, qual o método devo usar?

Perguntas de processos formativos atrelados a modelos instrumentais, ensino melhor se souber qual é o melhor modo de ensinar ou se souber como alguém aprende. Ou então, descrença em tudo aquilo que escapa, que varia daquele saber asséptico, sem vida, separado do campo problemático que o engendra, pois desprovido de seus nascimentos em invenção. Outras vezes, perguntas coladas a processos formativos ansiosos por pensar melhor, no âmbito da reflexão, para a mudança da ação. Se sei o melhor método, ensinarei de um melhor modo da próxima vez: Que seres bondosos, que moralizações ${ }^{7}$ estes modelos produzem! Eis que perdem toda a potência do acontecimento.

Naquela reunião, a recitação dos métodos já tão reconhecidos $e$ a apresentação de um método não reconhecido $e$ os modos de tornar seu um método ou outro $e$ a desconfiança do modo Adriana $e$ a não resposta do melhor método $e$ tantos outros fios, põem a funcionar um irreconhecível: embaralha-se códigos já engendrados numa matemática escolar, num saber e embaralha-se códigos de processos formativos, uma outra redistribuição se dá naquela configuração. Tudo se repete, mas não somos mais os mesmos. Entregues ao acaso, afirmando-o no que acontece, num único lance dos dados. Formar, um acontecimento, encontra sua própria necessidade.

\section{Referências}

CLARETO, S. M.; ROTONDO, M. S.; CAMMAROTA, G. Pesquisar em travessias: entre modos e fluxos esquizos, educações matemáticas. In: OLIVEIRA, A. M. P. de; ORTIGÃO, M. I. R. Abordagens teóricas e metodológicas nas pesquisas em

\footnotetext{
${ }^{6}$ Aqui é interessante destacar como Deleuze e Guattari (2010) irão dizer das três disciplinas, três filhas do caos, as Caóides, como forma de pensamento e criação. Essas caóides produzem realidades nos planos que recortam o caos. A filosofia produz a forma do conceito, num plano de imanência, ao trazer do caos, variações; a arte, num plano de composição, produz a força da sensação, quando traz do caos, variedades; e a ciência, num plano de referência, estará a cargo da função do conhecimento, a partir de variáveis. Disciplinas da produção do pensar, então do existir. Porém, sempre guardando uma aproximação com o caos, numa fuga à opinião. "A opinião nos apresenta uma ciência que sonharia com a unidade, com unificar suas leis, hoje ainda procuraria uma comunidade das quatro forças" (DELEUZE; GUATTARI, 2010, p. 242). Uma ciência, assim, é, pois totalizante, já que teoremática. Já a aproximação com o caos, no acontecimento, é um exercício de uma ciência problemática, não totalizante, uma ciência que "[...] daria toda unidade racional à qual aspira, por um pedacinho de caos que pudesse explorar” (DELEUZE; GUATTARI, 2010, p. 242). Há, nessa aproximação com o caos, nos três planos, uma experiência perturbadora e criadora, já que "[...] nenhuma criação existe sem experiência" (DELEUZE;GUATTARI, 2010, p. 152).

${ }^{7}$ Deleuze vai dizer que a imagem dogmática do pensamento, que aqui discutimos como constitutiva de modelos de formação que tomam a matemática como objeto de representação, é moral, “[...] pois só a Moral é capaz de nos persuadir de que o pensamento tem uma boa natureza, o pensador, uma boa vontade, e só o Bem pode fundar a suposta afinidade do pensamento com o Verdadeiro." (DELEUZE, 2006, p. 193).
} 
educação matemática. Brasília: Sbem, 2018. p. 282-297. Disponível em: < https://bityli.com/gI1xS >. Acesso em: 28 jan. 2019.

DELEUZE, G. Diferença e repetição. São Paulo: Graal, 2006.

. Quatro proposições sobre a psicanálise. In: DELEUZE, G. Dois regimes de loucos: textos e entrevistas (1975 - 1995). São Paulo: Editora 34, 2016. p. 82-90.

. Nietzsche e a filosofia. São Paulo: n-1 Edições , 2018.

DELEUZE, G.; GUATTARI, F. O que é a filosofia? Rio de Janeiro: Editora 34, 2010.

. O anti-édipo: capitalismo e esquizofrenia 1. São Paulo: Editora 34, 2011.

. Mil Platôs: Capitalismo e Esquizofrenia. v. 5. São Paulo: Editora 34, 2012.

. Kafka: por uma literatura menor. Belo Horizonte: Autêntica, 2015.

LAPOUJADE, D. Deleuze, os movimentos aberrantes. São Paulo: n-1 Edições, 2015.

LARROSA, J. Nietzsche \& a educação. Belo Horizonte: Autêntica, 2005

KASTRUP, V. Políticas cognitivas na formação do professor e o problema do devirmestre. Educação \& Sociedade, [s.1.], v. 26, n. 93, p. 1273-1288, dez. 2005. Disponível em: < http://dx.doi.org/10.1590/s0101-73302005000400010>. Acesso em: 25 jul. 2020.

. A invenção de si e do mundo: uma introdução do tempo e do coletivo no estudo da cognição. Belo Horizonte: Autêntica, 2007.

MELLO, E. M. Análise da dificuldade de alunos com o algoritmo da subtração. 2008a. 137 f. Dissertação (Mestrado em Educação Matemática) - Pontifícia Universidade Católica de São Paulo, São Paulo, 2008a. Disponível em: < https://bityli.com/XCX3f $>$. Acesso em: 25 jul. 2020.

- Análise de dificuldades de alunos do ensino fundamental com o uso do algoritmo da subtração. In: SIMPÓSIO INTERNACIONA DE PESQUISA EM EDUCAÇÃO MATEMÁTICA, 2., 2008b, Recife. Anais ... Recife: Ufpe, 2008. p. 1-7.

NUNES, T. et al. Educação matemática 1: números e operações numéricas. São Paulo: Cortez, 2009.

ROTONDO, M. A. S.; CAMMAROTA, G. Subtrair: Escola-pesquisar produzindo formação. In: ENCONTRO NACIONAL DE EDUCAÇÃO MATEMÁTICA, 13, 2016, São Paulo. Anais[...] . São Paulo: Sbem, 2016. p. 1 - 12. 
VERGNAUD, G. A teoria dos campos conceituais. In: BRUN, J. (Org.). Didáctica das matemáticas. Lisboa: Instituto Piaget, 1996. p. 155-191.

ZOURABICHVILI, F. Deleuze: uma filosofia do acontecimento. São Paulo: Editora 34, 2016. 